\title{
Evaluation of glycemic control and related factors among outpatients with type 2 diabetes at Tikur Anbessa Specialized Hospital, Addis Ababa, Ethiopia: a cross-sectional study
}

\author{
Rodas Getachew Abera ${ }^{1,2^{*}}$, Eyouel Shimeles Demesse ${ }^{1}$ and Wako Dedecha Boko ${ }^{1}$
}

\begin{abstract}
Background: The goals of glycemic management for patients with diabetes are to prevent or delay complications and optimize quality of life. However, in clinical practice, the recommended glycemic control target is difficult to achieve. Therefore, it is important to identify factors that influence the outcomes of glycemia to improve the quality of diabetic management.

The study aimed to evaluate the level and factors associated with glycemic control among type 2 diabetic outpatients at Tikur Anbessa Specialized Hospital, Addis Ababa, Ethiopia.

Methods: A hospital-based cross-sectional study was conducted among systematically selected 325 patients with type 2 diabetes who attended diabetic clinics at Tikur Anbessa Specialized Hospital. Pretested, structured, and interviewer-administered questionnaires were used to collect sociodemographic and diabetes-related information from March 1 to May 30, 2021. HbA1c was used to assess glycemic control according to the HbA1c target of < 7\% ('good' control) as recommended by the American Diabetes Association for non-pregnant adults. The HbA1c level in the range of 7-8\% was defined as 'inadequate' control and 'poor' at levels $>8 \%$. Data entry and analysis were performed using SPSS v26. Multivariate logistic regression analysis was used to identify determinants of glycemic control.

Results: The median level of HbA1c of the participants was 8.4\% (IQR 6.8-10.1). And approximately three-quarters (73.8\%) of the patients had inadequate and poor glycemic control (HbA1c $\geq 7 \%$ ). Older age (AOR: $2.46,95 \%$ Cl: $1.28-$ 6.01), DM duration of $>10$ years (AOR: 3.15, 95\% Cl: 2.22-6.54), insulin therapy (AOR: 3.07, 95\% Cl: 2.10-6.12), poor diet compliance (AOR: 1.97, 95\% Cl: 1.28-3.52) and failure to set goals for glycemic control (AOR: $3.42,95 \%$ Cl: $2.17-5.97$ ) were factors associated with inadequate and poor glycemic control.

Conclusions: The study revealed that a significant number of diabetic patients had inadequate and poor glycemic control levels. And this was associated with older age, longer duration of DM, insulin therapy, poor diet compliance, and failure to set control goals. This requires a focus on the associated factors identified and tailored management mechanisms to maintain good glycemic control.
\end{abstract}

Keywords: Diabetes mellitus, Blood glucose control, Glycosylated hemoglobin, Tikur Anbessa, Ethiopia

*Correspondence: rodasgetachew22@gmail.com

1 Department of Medical Laboratory Sciences, College of Health Sciences,

Addis Ababa University, Addis Ababa, Ethiopia

Full list of author information is available at the end of the article

\section{Background}

Diabetes mellitus (DM) is one of the main global health challenges of the twenty-first century. It is a metabolic disease characterized by chronic hyperglycemia caused 
by multiple etiologies, including defects in insulin secretion, action, or both [1]. Approximately 463 million adults (20-79 years) lived with diabetes worldwide in 2019 and about 4.2 million deaths were directly attributed to it $[2,3]$. Type $2 \mathrm{DM}$ is the most common form of $\mathrm{DM}$, accounting for ( $90 \%$ of patients), and the remaining $10 \%$ are type 1 diabetes or gestational diabetes. The prevalence of diabetes is rapidly increasing throughout the world, placing a severe economic burden on patients and society at large [4].

According to the International Diabetes Federation (IDF), an estimated 19.4 million adults aged $20-79$ years lived with diabetes in the IDF Africa Region in 2019, representing a regional prevalence of $3.9 \%$. The report also stated that Ethiopia is one of the most populous countries in Africa with the highest number of people with diabetes $(\sim 1.7$ million) with a prevalence rate of $3.2 \%$ among adults [5].

Many previous studies have assessed glycemic control levels among patients with type 2 diabetes in Ethiopia and reported a wide range of values. Cross-sectional hospital-based studies conducted in cities/towns of Dire Dawa, Jimma, Gondar, Nekemete, Addis Ababa, Dessie, Debre Tabor, Mettu, and Debre Markos showed that $45.2 \%, 54.7 \%, 60.5 \%, 64.9 \%, 68.3 \%, 70.8 \%, 71.4 \%, 72.7 \%$, $73.5 \%$ of the participants had poor glycemic control, respectively [6-14]. And this has been reported to be mainly associated with factors such as older age, longer duration of diabetes, insulin therapy, nonadherence to medications, poor diet adherence, and physical inactivity.

However, many, if not all, of these studies based their assessment on fasting blood glucose (FBG) levels. Very few have managed to measure the level of glycated hemoglobin (HbA1c) of participants. Using FBG over HbA1c, which is more accurate than the measurement of FBG to evaluate glycemic control, may not correctly represent the status of glycemic control of patients. FBG levels provide a short-term picture of control, while HbA1c is the most reliable indicator of long-term glycemic control as it accurately reflects an individual's blood glucose levels during the preceding 2-3 months [15]. The nonuse of the HbA1c test in previous studies was described as a limitation and the need for further studies using the HbA1c test was implied in several studies [9, 11, 13, 16-19], by the respective investigators.

According to a previous study conducted in Ethiopia, only $18.6 \%$ of the patients had a history of the HbA1c test [20]. Other studies stated that none of the studied diabetic patients had a determination of HbA1c [21-24]. Furthermore, although most of the factors associated with glycemic control have been discussed, modifiable risk factors such as setting glycemic target goals and the general approach and participation of healthcare providers, particularly physicians, with patients that are crucial to achieving good glycemic control were not fully investigated in previous studies.

Therefore, to fill the existing gaps and provide objective and reliable information on the level of glycemic control for standard care provision for patients, the present study sought to evaluate the status of glycemic control and the underlying factors associated with inadequate \& poor glycemic control among outpatients with T2DM using the National Glycohaemoglobin Standardization Program-certified (NGSP) and Diabetes Control \& Complications Trial-standardized (DCCT) HbA1c technique in a tertiary healthcare setting in Ethiopia.

\section{Methods}

\section{Study design, setting, and period}

A hospital-based cross-sectional study was conducted among patients with T2DM attending the outpatient medical diabetic clinic of Tikur Anbessa Specialized Hospital (TASH), Addis Ababa, Ethiopia. The study was carried out for 3 months from March 1 to May 30, 2021. TASH is the largest and busiest public referral and teaching hospital in the country. The hospital has a bed capacity of 800 and offers diagnosis and treatment for more than 500,000 patients a year. The hospital's endocrinology unit conducts two diabetes clinics a week and provides comprehensive diabetes care to approximately 800 to 1000 diabetic outpatients a month.

\section{Participant eligibility criteria}

All patients with T2DM who attended the outpatient medical diabetic clinic of TASH and who had followed up in the clinic for at least one year were included in the study with their consent. On the other hand, patients receiving erythropoietin or blood transfusion and those with anemia or conditions that affect erythrocyte production were excluded from the study. Additionally, critically ill patients and pregnant women were also excluded from the study.

\section{Study variables}

The dependent variable was the level of glycemic control (measured by the HbA1c test) and the independent variables were sociodemographic factors: age, sex, marital status, educational level, occupation, monthly income, residence, and access to healthcare. Clinical factors: duration of DM, family history of DM, body mass index (BMI), mode of therapy, presence of comorbidity, biochemical value. Behavioral factors: adherence to medications, adherence to diet, physical exercise, smoking, self-monitoring of blood glucose (SMBG), keeping up with follow-up visits, and setting glycemic target goals. 


\section{Sample size and sampling method}

The sample size was determined using a single population proportion formula considering a $59.4 \%$ proportion (p) of poor glycemic control as reported in an earlier study evaluated with HbA1c [7], with a confidence level of $95 \%$ and $5 \%$ marginal error $(\mathrm{d})$.

$$
\begin{aligned}
& n=\frac{\left(Z_{\propto} / 2\right)^{2} \times p(1-p)}{d^{2}} \\
& n=\frac{(1.96)^{2} \times 0.594 * 0.406}{(0.05)^{2}}=371
\end{aligned}
$$

The estimated average number of patients with T2DM expected to visit the diabetic clinic during the study period was $N=1434$. Since the source population (N) had less than 10,000 respondents, the sample size was adjusted with a correction formula $(n f)$ :

$$
n f=\frac{n}{1+\frac{n}{N}}=\frac{371}{1+\frac{371}{1434}}=295
$$

Assuming 10\% non-response rate: $(0.1) *(295) \approx 30$. $295+30=325$.

A systematic random sampling technique was used to select study participants at every $\mathrm{k}$-th interval. The actual sampling fraction $\left(\mathrm{k}^{\text {th }}\right)$ was determined by dividing the total number of the source population (1434) by the corrected sample size $(295) \approx 5$. Therefore, every fifth patient was approached and invited to participate in the study until the required sample size was reached.

\section{Data collection procedure}

Data were collected after the completion of the physician's office visit session. After obtaining informed consent from each study participant, information about sociodemographic, behavioral, and clinical characteristics was recorded through face-to-face interviews using structured and pre-tested questionnaires. The patient's medical records were also reviewed the same day after the interview to look for possible limiting factors that could interfere with the HbA1c test.

\section{Data collection tools Questionnaire}

The questionnaire was developed based on various similar previous studies [18, 25-28] and was further modified to include important variables from this study [see Additional file 1]. It was initially prepared in English, translated into Amharic, the local language, and retranslated into English again to ensure consistency. Data were collected in collaboration with outpatient department nurses \& laboratory personnel under close supervision by the principal investigators. The World Health Organization (WHO) safety guidelines and protocols for COVID19 were strictly followed at all times.

\section{Laboratory examination}

Laboratory investigations were performed for biochemical parameters: the level of glycated hemoglobin (HbA1c), fasting blood sugar (FBS), renal function test (RFT), and lipid profile [see Additional file 2]. $3 \mathrm{ml}$ of freshly drawn venous blood was collected in an EDTA tube for the determination of HbA1c by a turbidimetric immunoinhibition method using the fully automated Beckman Coulter DxC 700 AU clinical chemistry analyzer. The technique has been certified by the NGSP [29] and is not affected by common hemoglobin variants $(\mathrm{HbC}, \mathrm{HbS}, \mathrm{HbE}$, and $\mathrm{HbD}$ traits) and elevated fetal hemoglobin ( $\mathrm{HbF})$, minimizing inaccurate results for patients with these blood conditions [30]. $5 \mathrm{ml}$ of venous blood samples were also drawn from study participants in serum separation tubes (SST), in which serum was used to measure the FBS, RFT, and lipid profiles of patients using the same analyzer.

\section{Data quality assurance}

The quality of the data was ensured by properly designing the tool and the questionnaire was pre-tested in 5\% of the randomly selected patients with T2DM at St. Paul's Hospital Millennium Medical College before actual data collection, and some minor modifications were made accordingly. The principal investigators throughout the data collection process were in close contact and under close supervision. The completeness and consistency of the collected data were checked daily. Strict procedures were also implemented in the laboratory analysis of the analytes. A daily quality control test was performed for each analyte prior to sample analysis. Controls were also performed with each new lot of reagent and after specific maintenance or troubleshooting steps. A fasting-state blood sample was used for all analyte measurements. Samples were drawn into prelabeled barcoded SST and EDTA tubes, and quality \& quantity were checked. Blood samples collected in test tubes were processed with as little delay as possible and brought to the laboratory for evaluation of biochemical parameters on the same day. The results obtained were properly coded and documented.

\section{Data analysis and interpretation}

Data entry and analysis were performed using SPSS version 26. Descriptive statistics, including frequency, percentages, and median, were used to summarize baseline sociodemographic data from patients and evaluate the distribution of responses. Logistic regression analysis was 
conducted to look for any association between predictors and outcome variables. Factors with a P-value $<0.25$ in the bivariate analysis were exported to the multivariate logistic regression analysis. Multivariate analysis using logistic regression was performed to control the effect of potential confounder variables and to identify independent predictors of inadequate \& poor glycemic control. Consequently, statistically significant associations were determined based on the adjusted odds ratio (AOR) with its $95 \% \mathrm{CI}$ and the $P$-value $<0.05$.

Glycemic control was defined according to the HbA1c target of $<7 \%$ ('good' control) as recommended by the American Diabetes Association for non-pregnant adults. The HbAlc level in the range of $7-8 \%$ was defined as 'inadequate' control and 'poor' at levels greater than $8 \%$ [31].

\section{Operational definitions}

\section{Good glycemic control}

Glycemic control was considered good if a patient had a HbA1c value $<7 \%[31]$.

\section{Inadequate glycemic control}

Glycemic control was considered inadequate if a patient had $\mathrm{HbA} 1 \mathrm{c}$ values in the range of $7-8 \%$ [31].

\section{Poor glycemic control}

Glycemic control was considered poor if a patient had a HbA1c value $>8 \%$ [31].

\section{Adherence to medication}

if the study participant took all his/her antidiabetic medications in the last seven days [31].

\section{Adherence to diet}

If the study participant had followed the recommended diet for more than 3 days in the last seven days [31].

\section{Adherence to exercise}

If the study participant had followed the recommended level of exercise for more than 3 days in the last 7 days [31].

\section{Diabetes complications}

Harmful effects of diabetes, such as damage to the eyes, heart, blood vessels, nervous system, teeth and gums, feet, skin, or kidneys [31].

\section{Results}

Sociodemographic characteristics of the participants

A total of 325 patients with T2DM participated in the study. Among them, women comprised the majority of respondents, 186 (57.2\%). The median age of the participants was 54 years (IQR 45-62). Two hundred and seventeen $(66.8 \%)$ of the participants were married. One hundred twenty (36.9\%) had completed their secondary education \& one hundred six (32.6\%) were either in college or had already earned their degrees. One hundred fifty-eight $(48.6 \%)$ were government or private employees. More than half of the respondents $(53.8 \%)$ were urban dwellers. One hundred eleven (34.2\%) were making less than 1500 ETB a month. And a considerable number of study participants (60.6\%) had access to hospital services free of charge (Table 1).

Clinical characteristics and disease management practices The median duration of diabetes since diagnosis was 9 years (IQR 4-15). One hundred and fifty-three (47.1\%)

Table 1 Sociodemographic characteristics of study participants in TASH, Addis Ababa, Ethiopia, 2021

\begin{tabular}{|c|c|c|}
\hline Variables & Category & Frequency (\%) \\
\hline Age, median (IQR) & & 54 years $(45-62)$ \\
\hline \multirow[t]{4}{*}{ Age group (yrs.) } & $18-44$ & $74(22.8)$ \\
\hline & $45-54$ & $92(28.3)$ \\
\hline & $55-64$ & $101(31.1)$ \\
\hline & $\geq 65$ & $58(17.8)$ \\
\hline \multirow[t]{2}{*}{ Gender } & Male & $139(42.8)$ \\
\hline & Female & $186(57.2)$ \\
\hline \multirow[t]{4}{*}{ Marital status } & Single & $52(16)$ \\
\hline & Married & $217(66.8)$ \\
\hline & Divorced & $18(5.5)$ \\
\hline & Widow/er & $38(11.7)$ \\
\hline \multirow[t]{4}{*}{ Educational level } & No formal education & $37(11.4)$ \\
\hline & Primary ed. (grade 1-8) & $62(19.1)$ \\
\hline & Secondary ed. (grade 9-12) & $120(36.9)$ \\
\hline & College and above & $106(32.6)$ \\
\hline \multirow[t]{5}{*}{ Occupation } & Unemployed & $13(4)$ \\
\hline & Gov't/Private Employee & $158(48.6)$ \\
\hline & Self-employed & $95(29.2)$ \\
\hline & Homemaker & $24(7.4)$ \\
\hline & Retired/Pension & $35(10.8)$ \\
\hline \multirow[t]{3}{*}{ Monthly income (ETB) } & $<1500$ & $111(34.2)$ \\
\hline & $1500-5000$ & $130(40)$ \\
\hline & $>5000$ & $84(25.8)$ \\
\hline \multirow[t]{2}{*}{ Residence } & Urban & $175(53.8)$ \\
\hline & Rural & $150(46.2)$ \\
\hline \multirow[t]{2}{*}{ Healthcare access } & Free & $197(60.6)$ \\
\hline & Paid & $128(39.4)$ \\
\hline
\end{tabular}

$I Q R$ Interquartile Range, ETB Ethiopian Birr 
of the respondents implied that they had been living with diabetes for more than a decade. A family history of diabetes mellitus was recorded in at least one parent or child in $19.7 \%$ of the participants. Most of the respondents, $74.2 \%$ had a body mass index $\left(18.5-24.9 \mathrm{~kg} / \mathrm{m}^{2}\right)$, normal weight, while $19.1 \%$ appeared to be overweight $\left(25-29.9 \mathrm{~kg} / \mathrm{m}^{2}\right)$. Twelve $(3.7 \%)$ were obese $(\geq 30 \mathrm{~kg} /$ $\left.\mathrm{m}^{2}\right)$ and the remaining $3.1 \%$ fell within the underweight range $\left(<18.5 \mathrm{~kg} / \mathrm{m}^{2}\right)$. Comorbidities were present in almost $40 \%$ of the study participants. The most prevalent comorbidity was hypertension, which represented almost $20 \%$ of all comorbidities, followed by dyslipidemia (7.7\%) and ischemic heart disease (3.1\%). One hundred and fourteen (35.1\%) respondents have already developed one or more diabetic complications. Diabetic neuropathy was the most common diabetes complication (14.2\%) among the study participants. And 29 (9\%) of the respondents were affected by multiple complications related to diabetes.

Only twelve (3.7\%) of the participants were in a nonpharmacological mode of therapy. Most of the study participants (44.6\%) used insulin, 93 (28.6\%) were on oral hypoglycemic agents, and the rest $75(23.1 \%)$ used combinations of insulin and oral hypoglycemic agents.

Over $50 \%$ of the participants had routine follow-up visits more than three times a year. About $70 \%$ adhered fully to their prescribed medications during the previous week before the study. A little more than half of the respondents 168 (51.7\%) followed the recommended healthy eating plan adequately. And 138 (42.5\%) participated in at least 30 min of physical activity for more than 3 days a week. $41.8 \%$ of the respondents have the means to self-monitor their blood glucose levels, own a glucometer, and the rest access nearby clinics or pharmacies. As few as eight (2.5\%) participants were active smokers. And around $40 \%$ of the respondents indicated that they have set a glycemic target goal for management, which they strive to achieve (Table 2).

\section{Glycemic control \& biochemical parameters}

The median level of HbA1c of the study participants was found to be $8.4 \%$ (IQR 6.8-10.1). Good glycemic control was achieved only in 85 (26.2\%) of the total respondents, according to the criteria of the American Diabetes Association of less than $7 \%$. About $17 \%$ had inadequate control (7-8\%). And more than half of the participants (56.9\%) had poor glycemic control (>8\%) (Fig. 1). Fasting blood sugar level was greater than or equal to $130 \mathrm{mg} /$ $\mathrm{dL}$ in $58.2 \%$ of the respondents, while approximately $80 \%$ of the respondents had a total cholesterol value below $200 \mathrm{mg} / \mathrm{dL}$ (Table 3).

\section{Factors associated with inadequate and poor glycemic control}

In bivariate logistic regression: age, sex, duration since diagnosis of diabetes, body mass index, mode of therapy, adherence to diet, physical exercise, glycemic target goals, and comorbidities were associated with glycemic control and exported to the multivariate logistic regression model.

The results of the multivariate logistic regression analysis to identify factors associated with inadequate \& poor glycemic control showed that older age, duration of DM of more than 10 years, insulin therapy, adherence to diet less than 3 days a week, and failure to set glycemic target goals were factors associated with inadequate \& poor glycemic control (AOR: 2.46, 95\% CI: 1.28-6.01, $P=0.03$ ), (AOR: 3.15, 95\% CI: 2.22-6.54, $P=0.016$ ), (AOR: 3.07, 95\% CI: 2.10-6.12, $P=0.022$ ), (AOR: 1.97, 95\% CI: 1.28-3.52, $P=0.002$ ) and (AOR: 3.42, 95\% CI: 2.17-5.97, $P=0.001)$, respectively.

The study showed that older age individuals with diabetes, specifically in the age category of (55-64) years, tend to have inadequate \& poor control over their blood sugar levels compared to their younger counterparts. Patients with diabetes mellitus for more than ten years were found to be 3.15 times more likely to have inadequate \& poor glycemic control than those with shorter durations. And the odds of having inadequate \& poor glycemic control were found to be 3.07 times higher among patients on insulin therapy than among those on different treatment regimens. Furthermore, there was also a noticeable difference in adherence to a diet. Study participants who adhered to a diet for less than 3 days a week were approximately twice as likely to have inadequate \& poor blood glucose control compared to those who adhered to the recommended healthy eating plan adequately. Finally, patients without established glycemic target goals were found to be 3.42 times more likely to have inadequate \& poor glycemic control than those who established one (Table 4).

\section{Discussion}

Measurement of HbA1c is considered an important diagnostic tool in monitoring diet control and therapeutic regimes during the treatment of diabetes. To our knowledge, this is the first study to evaluate the state of glycemic control using the NGSP certified and DCCT standardized HbA1c assay method and to highlight the determinants of inadequate \& poor glycemic control in TASH. The study findings showed that almost threequarters $(73.8 \%)$ of the study participants had inadequate and poor glycemic control (HbA1c $\geq 7 \%)$. The prevalence 
Table 2 Clinical characteristics and disease management practices of study participants in TASH, Addis Ababa, Ethiopia, 2021

\begin{tabular}{|c|c|c|}
\hline Variables & Category & Frequency (\%) \\
\hline DM duration, median (IQR) & & 9 years (4-15) \\
\hline \multirow[t]{3}{*}{ Duration of DM } & $2-5$ years & $50(15.4)$ \\
\hline & $6-10$ years & $122(37.5)$ \\
\hline & $\geq 11$ years & $153(47.1)$ \\
\hline \multirow[t]{2}{*}{ Family history of DM } & Yes & $64(19.7)$ \\
\hline & No & $261(80.3)$ \\
\hline \multirow[t]{4}{*}{$\mathrm{BMI}\left(\mathrm{kg} / \mathrm{m}^{2}\right)$} & Underweight $(<18.5)$ & $10(3.1)$ \\
\hline & Normal weight (18.5-24.9) & $241(74.2)$ \\
\hline & Overweight (25-29.9) & $62(19.1)$ \\
\hline & Obese $(\geq 30)$ & $12(3.7)$ \\
\hline \multirow[t]{4}{*}{ Mode of therapy } & Oral hypoglycemic agents & $93(28.6)$ \\
\hline & Insulin & $145(44.6)$ \\
\hline & Combination of both & $75(23.1)$ \\
\hline & Diet modification/Exercise alone & $12(3.7)$ \\
\hline \multirow[t]{2}{*}{ No. of follow-up visits } & $\leq 3$ times/year & $156(48)$ \\
\hline & $>3$ times/year & $169(52)$ \\
\hline \multirow{2}{*}{$\begin{array}{l}\text { Medication adherence } \\
(n=313)\end{array}$} & 7 days/week (adequate) & $228(70.2)$ \\
\hline & $<7$ days/week (inadequate) & $85(26.2)$ \\
\hline \multirow[t]{2}{*}{ Diet adherence } & > 3 days/week (adequate) & $168(51.7)$ \\
\hline & 0-3 days/week (inadequate) & $157(48.3)$ \\
\hline \multirow[t]{2}{*}{ Physical exercise } & >3 days/week (Adequate) & $138(42.5)$ \\
\hline & 0-3 days/week (Inadequate) & $187(57.5)$ \\
\hline \multirow[t]{2}{*}{ Access to SMBG } & Yes & $136(41.8)$ \\
\hline & No & $189(58.2)$ \\
\hline \multirow[t]{2}{*}{ Glycemic targets goal (HbA1c/FBS/RBS) } & Yes & $129(39.7)$ \\
\hline & No & $196(60.3)$ \\
\hline \multirow[t]{3}{*}{ Smoking status } & Current smoker & $8(2.5)$ \\
\hline & Ex-smoker (> 1 year) & $16(4.9)$ \\
\hline & Nonsmoker & $301(92.6)$ \\
\hline \multirow[t]{2}{*}{ Co-morbidity } & Present & $129(39.7)$ \\
\hline & Absent & $196(60.3)$ \\
\hline \multirow[t]{5}{*}{ Type of co-morbidity(ies) } & Hypertension & $63(19.4)$ \\
\hline & Dyslipidemia & $25(7.7)$ \\
\hline & Ischemic heart disease (IHD) & $10(3.1)$ \\
\hline & Hypertension + IHD & $7(2.2)$ \\
\hline & Others* & $24(7.4)$ \\
\hline \multirow[t]{2}{*}{ Complication } & Present & $114(35.1)$ \\
\hline & Absent & $211(64.9)$ \\
\hline \multirow[t]{5}{*}{ Type of complication(s) } & Neuropathy & $46(14.2)$ \\
\hline & Retinopathy & $23(7.1)$ \\
\hline & Retinopathy + Neuropathy & $21(6.5)$ \\
\hline & Retinopathy + Neuropathy + Nephropathy & $8(2.5)$ \\
\hline & Cardiac complications & $16(4.9)$ \\
\hline
\end{tabular}

Others*-Asthma, Thyroid disorders \& Obesity

$B M I$ Body Mass Index, SMBG Self-monitoring of blood glucose, HbA1c Hemoglobin A1c, FBS Fasting blood sugar, RBS Random blood sugar

of inadequate \& poor glycemic control status was comparable to previous studies conducted in Saudi Arabia (74.9\%) [28], Ghana (70\%) [32], Uganda (73.52\%) [33] and Northeast Ethiopia (70.8\%) [11]. However, the magnitude of inadequate and poor glycemic control status in the current study was greater than previously reported in 


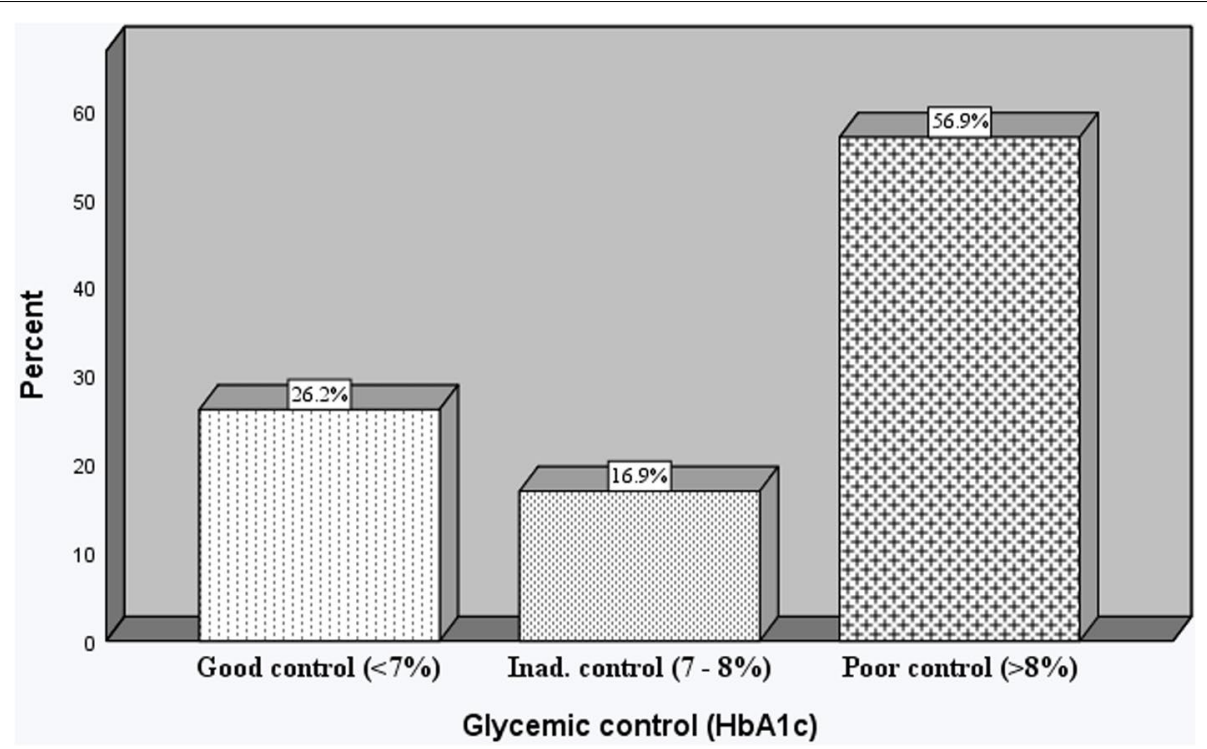

Fig. 1 Level of glycemic control among patients with T2DM at TASH, Addis Ababa, Ethiopia, 2021

Table 3 Biochemical parameters of the study participants in TASH, Addis Ababa, Ethiopia, 2021

\begin{tabular}{lll}
\hline Parameters & Category & Frequency (\%) \\
\hline HbA1c level, median (IQR) & & $8.4 \%(6.8-10.1)$ \\
FBS (mg/dL) & $<130$ & $136(41.8)$ \\
& $\geq 130$ & $189(58.2)$ \\
Total cholesterol (mg/dL) & $<200$ & $259(79.7)$ \\
& $\geq 200$ & $66(20.3)$ \\
Triglyceride (mg/dL) & $<150$ & $210(64.6)$ \\
& $\geq 150$ & $115(35.4)$ \\
HDL-C (mg/dL) & M: $\geq 40, F: \geq 50$ & $171(52.6)$ \\
& $M:<40, F:<50$ & $154(47.4)$ \\
LDL-C (mg/dL) & $<130$ & $211(64.9)$ \\
& $\geq 130$ & $114(35.1)$ \\
Urea (mg/dL) & $10-50$ & $308(94.8)$ \\
Creatinine (mg/dL) & $>50$ & $17(5.2)$ \\
& $0.5-1.2$ & $297(91.4)$ \\
\hline
\end{tabular}

HDL-C High-density lipoprotein cholesterol, LDL-C Low-density lipoprotein cholesterol

the United States (69\%) [34], India (37.5\%) [27], Tanzania (49.8\%) [35], North West Ethiopia (60.5\%) [36], Addis Ababa, Ethiopia (68.3\%) [10] and East Ethiopia (45.2\%) [6]. The higher proportion of poor glycemic control in the present study than previous studies conducted in parts of the country could be that patients seeking advanced treatment were referred to the Tikur Anbessa Specialized Hospital. However, the finding in the present study appeared to be lower than some studies reported in Nigeria (83.3\%) [37], Kenya (81.6\%) [38], and Addis Ababa, Ethiopia (80\%) [24]. Although the studies mentioned above had the same study design and comparable sample sizes, there were variations in the reported numbers. The discrepancy between the present and previous studies conducted in sub-Saharan Africa, particularly Ethiopia, may have arisen mainly from differences in the types and methods of glucose measurement. Some researchers based their studies on FBS measurements and others on HbA1c. The other is the use of different assay methods, especially in the case of $\mathrm{HbA} 1 \mathrm{c}$ determination, where the use of assays outside those certified by NGSP and standardized by DCCT gives falsely high or low readings in patients with hemoglobin variants and therefore compromises the comparability between $\mathrm{HbA1c}$ laboratories [29]. Other factors related to the clinical and sociodemographic characteristics of the study participants may also have contributed to the observed variations.

Older age, duration of DM of more than 10 years, insulin therapy, adherence to diet fewer than 3 days a week, and failure to set glycemic target goals were significantly associated with inadequate \& poor glycemic control. The study showed that older age individuals with diabetes, specifically 55 years and older, tend to have inadequate \& poor control over their blood glucose levels compared to their younger counterparts. This finding is consistent with results from previous studies $[9,37]$. This could be explained in part due to the less stringent glycemic goal approach for older adult patients considering factors such as limited life expectancy, extensive comorbid conditions, 
Table 4 Bivariate and multivariate logistic regression analyses of factors associated with glycemic control among patients with T2DM in TASH, Addis Ababa, Ethiopia, 2021

\begin{tabular}{|c|c|c|c|c|c|c|c|}
\hline \multirow[t]{2}{*}{ Variable } & \multirow[t]{2}{*}{ Category } & \multicolumn{2}{|c|}{ Glycemic control (HbA1c) } & \multicolumn{2}{|c|}{ Bivariate Analysis } & \multicolumn{2}{|c|}{ Multivariate Analysis } \\
\hline & & $\begin{array}{l}\text { Good } \\
(<7 \%) \\
n=85\end{array}$ & $\begin{array}{l}\text { Inadequate- } \\
\text { poor } \\
(\geq 7 \%) \\
n=240\end{array}$ & COR $(95 \% \mathrm{Cl})$ & P-value & AOR $(95 \% \mathrm{Cl})$ & P-value \\
\hline \multirow[t]{4}{*}{ Age group (yrs.) } & $18-44$ & 26 & 48 & 1 & - & 1 & - \\
\hline & $45-54$ & 26 & 66 & $0.74(0.39-1.18)$ & $0.042^{*}$ & $1.63(0.66-4.18)$ & 0.11 \\
\hline & $55-64$ & 16 & 85 & $1.90(1.10-3.20)$ & $0.002^{*}$ & $2.46(1.28-6.01)$ & $0.03^{*}$ \\
\hline & $\geq 65$ & 17 & 41 & $1.72(1.02-3.06)$ & $0.008^{*}$ & $1.97(1.30-5.97)$ & $0.04^{*}$ \\
\hline \multirow[t]{2}{*}{ DM duration } & $\leq 10$ years & 72 & 100 & 1 & - & 1 & - \\
\hline & $>10$ years & 33 & 120 & $1.62(1.13-3.43)$ & $0.001^{*}$ & $3.15(2.22-6.54)$ & $0.016^{*}$ \\
\hline \multirow[t]{4}{*}{ Mode of therapy } & Oral hypoglycemic agents (OHA) & 46 & 47 & 1 & - & 1 & - \\
\hline & Insulin & 41 & 104 & $2.50(1.30-4.50)$ & $0.001^{*}$ & $3.07(2.10-6.12)$ & $0.022^{*}$ \\
\hline & OHA \& Insulin & 25 & 50 & $1.12(0.24-3.72)$ & $0.029^{*}$ & $2.36(0.82-5.97$ & 0.073 \\
\hline & Diet modification/Exercise alone & 11 & 1 & $0.52(0.38-2.88)$ & 0.054 & $0.91(0.52-3.53)$ & 0.160 \\
\hline \multirow[t]{2}{*}{ Diet adherence } & $>3$ days/week & 80 & 88 & 1 & - & 1 & - \\
\hline & 0-3 days/week & 45 & 112 & $2.32(1.35-3.99)$ & $0.001^{*}$ & $1.97(1.28-3.52)$ & $0.002^{*}$ \\
\hline \multirow{2}{*}{$\begin{array}{l}\text { Glycemic target goal } \\
\text { (HbA1c/FBS/RBS) }\end{array}$} & Yes & 82 & 47 & 1 & - & 1 & - \\
\hline & No & 49 & 147 & $2.61(1.90-4.82)$ & $0.001^{*}$ & $3.42(2.17-5.97)$ & $0.001 *$ \\
\hline
\end{tabular}

${ }^{*}$ Statistically significant

COR Crude Odds Ratio, AOR Adjusted Odds Ratio, Cl Confidence Interval

and advanced microvascular or macrovascular complications, where the risk and burden outweigh the potential benefits of intensive control. Unlike these findings, older age was associated with good glycemic control in a study conducted in Palestine [39]. Elsous et al. associated older age with literacy, knowledgeability \& experience and concluded that older individuals were more likely to have well-controlled glycemic levels, which was not the case in the present study. Some other studies also had similar results $[32,36]$.

Patients with a longer duration of DM ( $>10$ years) were found to be 3.15 times more likely to have inadequate \& poor glycemic control than those with a shorter duration of the disease. And this finding is commonly shared among many related studies [14, 18, 34, 40]. Due to the chronic and progressive nature of diabetes, patients with a longer duration of the disease may eventually find it difficult to maintain good glycemic control. Impaired insulin secretion due to beta-cell dysfunction could explain this [41]. In line with previous studies [33, 39, 42], the odds of having inadequate \& poor glycemic control were higher (3.07 times) among patients receiving insulin therapy than among those receiving different treatment regimens. Many patients with T2DM eventually need insulin therapy once the progression of the disease overcomes the effect of hypoglycemic agents [43]. This could be the reason for the increased prevalence of inadequate \& poor glycemic control status among insulin users.
Non-compliance with diet recommendations was also associated with inadequate \& poor glycemic control. Study participants who adhered to a diet for less than 3 days a week were approximately twice as likely to have inadequate and poor blood glucose control compared to those who adhered adequately to the recommended healthy eating plan, which was also highlighted in some other studies $[13,44]$. Finally, patients who did not set target goals for glycemic management were 3.42 times more likely to have inadequate \& poor glycemic control than those with an established plan. This could be due to a lack of awareness of target blood glucose levels to manage diabetes among diabetes patients, which has also been reflected in recently conducted studies [24, 45]. Furthermore, only $41.8 \%$ of the respondents were found to have the means to self-monitor their blood glucose levels, owning a glucometer, while the remaining $58.2 \%$ had to regularly visit nearby clinics or pharmacies to check their blood glucose levels. The numbers may be higher than reported in previous studies [ 44 , 46,47 ], but this could be because most of the participants in the present study resided in urban areas. Given the high prevalence of diabetes in the country, the access and distribution of SMBG devices are still far from sufficient.

\section{Strength and limitations}

This study is the first to use the NGSP-certified/DCCTstandardized HbA1c method to assess the level of glycemic control and the factors associated with it among 
diabetic patients at Tikur Anbessa Specialized Hospital. However, the study adopted a cross-sectional study design and comprised a relatively smaller number of participants.

\section{Conclusions and recommendations}

The results of this study showed that approximately three-quarters $(73.8 \%)$ of the study participants had inadequate \& poor glycemic control, which is far below the recommended standards. And this was found to be associated with factors such as older age, longer duration of DM, insulin therapy, poor diet compliance, and failure to set control goals. This calls for a focus on the associated factors identified and tailored management mechanisms to maintain good glycemic control.

Greater efforts must be made to address the factors associated with inadequate \& poor glycemic control and optimize quality of life. Special attention should be paid to elderly patients, those with a longer duration of DM, and those on insulin therapy by increasing the frequency of hospital follow-up visits to assess and closely monitor their health status. Many previously conducted studies have also highlighted the factors mentioned above associated with poorly controlled diabetes. Therefore, increasing follow-up visits for patients with similar conditions could prove vital to achieving good glycemic control.

Various awareness initiatives should be held on diabetes care and ways of self-management of the disease. As type 2 diabetes can be progressive, patients should actively participate in the management process. They must be aware of the benefits of leading a healthy lifestyle and advised to strictly adhere to a healthy eating plan and engage in physical activity as often as possible. In addition, patients need the help of healthcare providers, especially physicians, to set a glycemic target to manage diabetes. Target goals should be individualized considering the duration of DM, age/life expectancy, comorbidities, advanced microvascular or macrovascular complications, unawareness of hypoglycemia, and the preference of the individual patient, as recommended by the American Diabetic Association. More stringent targets $(\mathrm{HbA} 1 \mathrm{c}<6.5 \%)$ are suggested for patients with $\mathrm{DM}$ of short duration, long life expectancy, and no significant cardiovascular disease (CVD) if they can be achieved safely without inducing significant hypoglycemia. Less stringent goals (HbA1c up to 8\%) are recommended for patients with limited life expectancy, significant comorbidities, advanced microvascular or macrovascular complications, and those with frequent or severe episodes of hypoglycemia. The target goals should also be reevaluated over time to balance risks and benefits as patient factors change. In general, doctor office visits should be participatory and patients should actively participate in a shared decision-making process with clinicians on matters related to their health and care to better implement diabetes care goals.

In addition, to provide standard care to patients, objective and reliable information is needed on the magnitude of glycemic control. In this regard, clinically effective and reliable results should be obtained using $\mathrm{HbA1c}$ methods certified by the NGSP and standardized by the DCCT. Furthermore, a concerted effort is needed to increase the access and availability of tools for self-monitoring blood glucose levels. More research is warranted with a larger sample to ensure representativeness and investigate the association between glycemic control and different factors that progressively affect it.

\section{Abbreviations}

DCCT: Diabetes Control and Complications Trial; DM: Diabetes mellitus; FBG: Fasting blood glucose; HbA1c: Glycated hemoglobin; NGSP: National Glycohaemoglobin Standardization Program; T2DM: Type 2 diabetes mellitus; TASH: Tikur Anbessa Specialized Hospital.

\section{Supplementary Information}

The online version contains supplementary material available at https://doi. org/10.1186/s12902-022-00974-z.

Additional file 1. (PDF $166 \mathrm{~kb}$ )

Additional file 2. (DOCX $35 \mathrm{~kb}$ )

Acknowledgements

The authors thank all participants who participated in this study.

Authors' contributions

RGA conceived and designed the study, participated in data collection, performed laboratory \& data analysis, and drafted the manuscript. ESD and WDB participated in the review and editing of the manuscript. All authors read and approved the final manuscript.

\section{Funding}

The study was sponsored by Addis Ababa University. The Funder had no role in the design of the study, the collection, analysis, and interpretation of the data, nor in the writing of the manuscript.

Availability of data and materials

All relevant data are within the manuscript and its supporting files.

\section{Declarations}

\section{Ethics approval and consent to participate}

This study was carried out in accordance with the principles of the Declaration of Helsinki. Ethical clearance was obtained from the Research and Ethics Review Committee (DRERC) of the Department of Medical Laboratory Sciences of the College of Health Sciences of Addis Ababa University (DRERC/590/21/MLS). A permission letter was also granted from the TASH Endocrinology Unit. Furthermore, prior to data collection, each patient was taken through the consent process and willingness to participate in the study was affirmed by obtaining written consent.

\section{Consent for publication}

Not applicable. 


\section{Competing interests}

The authors have declared that no competing interests exist.

\section{Author details}

'Department of Medical Laboratory Sciences, College of Health Sciences, Addis Ababa University, Addis Ababa, Ethiopia. ${ }^{2}$ Tikur Anbessa Specialized Hospital, College of Health Sciences, Addis Ababa University, Addis Ababa, Ethiopia.

Received: 18 November 2021 Accepted: 25 February 2022

Published online: 07 March 2022

\section{References}

1. Classification and diagnosis of diabetes. Standards of Medical Care in Diabetes. Diabetes Care. 2020;43(Supplement 1):S14-31.

2. Diabetes. Who.int. 2020 [cited 14 May 2021]. Available from: https://www. who.int/health-topics/diabetes

3. International Diabetes Federation. IDF Diabetes Atlas. 9th ed. Brussels, Belgium: International Diabetes Federation; 2019.

4. Diabetes. Who.int. 2020 [cited 14 May 2021]. Available from: https://www. who.int/news-room/fact-sheets/detail/diabetes

5. Diabetes in Africa. Idf.org. 2021 [cited 24 July 2021]. Available from: https:// idf.org/our-network/regions-members/africa/diabetes-in-africa.html

6. Nigussie S, Birhan N, Amare F, Mengistu G, Adem F, Abegaz TM. Rate of glycemic control and associated factors among type two diabetes mellitus patients in Ethiopia: a cross-sectional study. PLoS One. 2021;16(5):e0251506. https://doi.org/10.1371/journal.pone.0251506.

7. Cheneke W, Suleman S, Yemane T, Abebe G. Assessment of glycemic control using glycated hemoglobin among diabetic patients in Jimma University specialized hospital, Ethiopia. BMC Res Notes. 2016;9(1):96. https://doi.org/10.1186/s13104-016-1921-x.

8. Feleke BE, Feleke TE, Kassahun MB, Adane WG, Fentahun N, Girma A, et al. Glycemic control of diabetes mellitus patients in referral hospitals of Amhara region, Ethiopia: a cross-sectional study. Biomed Res Int. 2021;2021:6691819. https://doi.org/10.1155/2021/6691819.

9. Fekadu G, Bula K, Bayisa G, Turi E, Tolossa T, Kasaye HK. Challenges And factors associated with poor glycemic control among type 2 diabetes mellitus patients at nekemte referral hospital Western Ethiopia. J Multidiscip Healthc. 2019;12:963-74. https://doi.org/10.2147/JMDH.S232691.

10. Demoz GT, Gebremariam A, Yifter H, Alebachew M, Niriayo YL, Gebreslassie $\mathrm{G}$, et al. Predictors of poor glycemic control among patients with type 2 diabetes on follow-up care at a tertiary healthcare setting in Ethiopia. BMC Res Notes. 2019;12(1):207. https://doi.org/10.1186/ s13104-019-4248-6.

11. Fiseha T, Alemayehu E, Kassahun W, Adamu A, Gebreweld A. Factors associated with glycemic control among diabetic adult out-patients in Northeast Ethiopia. BMC Res Notes. 2018;11(1):316. https://doi.org/10. 1186/s13104-018-3423-5.

12. Gebermariam AD, Tiruneh SA, Ayele AA, Tegegn HG, Ayele BA, Engidaw M. Level of glycemic control and its associated factors among type II diabetic patients in Debre Tabor general hospital, northwest Ethiopia. Metab Open. 2020;8:100056. https://doi.org/10.1016/j.metop.2020.100056.

13. Sheleme T, Mamo G, Melaku T, Sahilu T. Glycemic control and its predictors among adult diabetic patients attending Mettu Karl referral hospital, Southwest Ethiopia: a prospective observational study. Diabetes Ther. 2020;11(8):1775-94. https://doi.org/10.1007/s13300-020-00861-7.

14. Gebrie A, Tesfaye B, Sisay M. Evaluation of glycemic control status and its associated factors among diabetes patients on follow-up at referra hospitals of Northwest Ethiopia: a cross-sectional study, 2020. Heliyon. 2020;6(12):e05655. https://doi.org/10.1016/j.heliyon.2020.e05655.

15. Sherwani SI, Khan HA, Ekhzaimy A, Masood A, Sakharkar MK. Significance of $\mathrm{HbA} 1 \mathrm{c}$ test in diagnosis and prognosis of diabetic patients. Biomark Insights. 2016;11:95-104.

16. Kassahun T, Eshetie T, Gesesew H. Factors associated with glycemic control among adult patients with type 2 diabetes mellitus: a cross-sectional survey in Ethiopia. BMC Res Notes. 2016;9(1):78. https://doi.org/10.1186/ s13104-016-1896-7.

17. Yigazu DM, Desse TA. Glycemic control and associated factors among type 2 diabetic patients at Shanan Gibe Hospital, Southwest
Ethiopia. BMC Res Notes. 2017;10(1):597. https://doi.org/10.1186/ s13104-017-2924-y.

18. Mamo Y, Bekele F, Nigussie T, Zewudie A. Determinants of poor glycemic control among adult patients with type 2 diabetes mellitus in Jimma University Medical Center, Jimma zone, southwest Ethiopia: a casecontrol study. BMC Endocr Disord. 2019;19(1):91. https://doi.org/10.1186/ s12902-019-0421-0.

19. Dedefo MG, Abate SK, Ejeta BM, Korsa AT. Predictors of poor glycemic control and level of glycemic control among diabetic patients in west Ethiopia. Ann Med Surg. 2020;55:238-43.

20. Belay E, Abera A, Mehari A, Gebremeskel G, Endrias A, Endris K. Achievements of diabetes goals and their determinants in type 2 diabetic patients attending outpatient diabetic clinic in Northern Ethiopia. Int J Chronic Dis. 2017;2017:1-8. https://doi.org/10.1155/2017/5713187.

21. Feleke $Y$, Enquselassie F. An assessment of the health care system for diabetes in Addis Ababa Ethiopia. Ethiop J Heal Dev. 2006;19(3):203-10.

22. Gudina EK, Amade ST, Tesfamichael FA, Ram R. Assessment of quality of care given to diabetic patients at Jimma University Specialized Hospital diabetes follow-up clinic, Jimma, Ethiopia. BMC Endocr Disord. 2011:11(1):19. https://doi.org/10.1186/1472-6823-11-19.

23. Hailu E, Mariam WH, Belachew T, Birhanu Z. Self-care practice and glycaemic control amongst adults with diabetes at the Jimma University Specialized Hospital in south-west Ethiopia: a cross-sectional study. Afr J Prim Health Care Fam Med. 2012;4(1):311. https://doi.org/10.4102/ phcfm.v4i1.311.

24. Tekalegn Y, Addissie A, Kebede T, Ayele W. Magnitude of glycemic control and its associated factors among patients with type 2 diabetes at Tikur Anbessa Specialized Hospital, Addis Ababa, Ethiopia. PLoS One. 2018;13(3):e0193442. https://doi.org/10.1371/journal.pone.0193442.

25. Dussa K, Parimalakrishnan S, Sahay R. Assessment of diabetes knowledge using diabetes knowledge questionnaire among people with type 2 diabetes mellitus. Asian J Pharm Clin Res. 2015;8(2):254-6.

26. Yifter H, Reja A, Ahmed A, Narayan KM, Amogne W. Achievement of diabetes care goals at Tikur Anbessa Specialized Hospital, Addis Ababa. Ethiopia Ethiop Med J. 2020;58:125-30.

27. Pan T, Dasgupta A, Suman S, Paul B, Banerjee R, Burman J. Assessment of glycaemic control in patients with type 2 diabetes: a clinicbased study in a slum of Kolkata. Int J Community Med Public Heal. 2018;5(11):4768-72.

28 Badedi M, Solan Y, Darraj H, Sabai A, Mahfouz M, Alamodi S, et al. Factors associated with long-term control of type 2 diabetes mellitus. J Diabetes Res. 2016;2016:2109542. https://doi.org/10.1155/2016/2109542.

29. NGSP Certified Methods/Labs. Ngsp.org. 2021 [cited 23 December 2020]. Available from: http://www.ngsp.org/certified.asp

30. NGSP: HbA1c Assay Interferences. Ngsp.org. 2021 [cited 21 July 2021]. Available from: http://www.ngsp.org/interf.asp

31. ADA. Glycemic targets: Standards of medical care in diabetes-2020. Diabetes Care. 2020;43(Supplement 1):S66-76.

32. Mobula LM, Sarfo FS, Carson KA, Burnham G, Arthur L, Ansong D, et al, Predictors of glycemic control in type-2 diabetes mellitus: evidence from a multicenter study in Ghana. Transl Metab Syndr Res. 2018;1:1-8. https:// doi.org/10.1016/j.tmsr.2018.09.001.

33. Kibirige D, Akabwai GP, Kampiire L, Kiggundu DS, Lumu W. Frequency and predictors of suboptimal glycemic control in an African diabetic population. Int J Gen Med. 2017;10:33-8. https://doi.org/10.2147/IJGM.S124548.

34. Milo RB, Connelly CD. Predictors of glycemic management among patients with type 2 diabetes. J Clin Nurs. 2019;28:1737-44. https://doi. org/10.1111/jocn.14779.

35. Gunda DW, Bandali HA, Malindisa EK, Kidenya BR. Use of HBA1c and potentiality of gender, missed medication and fasting glucose in the prediction of poor glycemic control in resource-limited setting; a clinicbased case-control study. PAMJ - One Health. 2020;2:22. https://doi.org/ 10.11604/pamj-oh.2020.2.22.22624.

36. Fasil A, Biadgo B, Abebe M. Glycemic control and diabetes complications among diabetes mellitus patients attending at University of Gondar Hospital Northwest Ethiopia. Diabetes Metab Syndr Obes. 2019:12:75-83. https://doi.org/10.2147/DMSO.S185614.

37. Anioke IC, Ezedigboh AN, Dozie-Nwakile OC, Chukwu IJ, Kalu PN. Predictors of poor glycemic control in adult with type 2 diabetes in South-Eastern Nigeria. Afr Health Sci. 2019;19(4):2819-28. https://doi.org/10.4314/ ahs.v19i4.3. 
38. Nduati NJ. Factors associated with glycemic control among type 2 diabetes patients attending Mathari National Teaching Hospital, Nairobi Kenya. J Endocrinol Diabetes. 2016;3(6):1-11. https://doi.org/10.15226/ 2374-6890/3/6/00162.

39. Radwan M, Elsous A, Al-Sharif H, Abu MA. Glycemic control among primary care patients with type 2 diabetes mellitus in the Gaza Strip Palestine. Ther Adv Endocrinol Metab. 2018;9(1):3-14. https://doi.org/10. 1177/2042018817742070.

40. Alzaheb RA, Altemani AH. The prevalence and determinants of poor glycemic control among adults with type 2 diabetes mellitus in Saudi Arabia. Diabetes Metab Syndr Obes. 2018;11:15-21. https://doi.org/10. 2147/DMSO.S156214.

41. American Diabetes Association. Standards of Medical care in diabetes 2019. Diabetes Care. 2019;42(Suppl 1):S1-193.

42. Afroz A, Ali L, Karim MN, Alramadan MJ, Alam K, Magliano DJ, et al. Glycaemic control for people with type 2 diabetes mellitus in Bangladesh - an urgent need for optimization of management plan. Sci Rep. 2019;9(1):10248.

43. Rodríguez-Gutiérrez R, Quintanilla-Flores DL, Portillo-Sánchez P, HinojosaAmaya JM, Morey-Vargas OL, Montori VM, et al. Diabetes Mellitus (DM). McMaster Textbook of Internal Medicine. https://empendium.com/ mcmtextbook/chapter/B31.II.13.1 Accessed July 21, 2021 .

44. Mariye T, Bahrey D, Tasew H, Teklay G, Gebremichael GB, Teklu T, et al. Determinants of Poor Glycemic Control among Diabetes Mellitus Patients in Public Hospitals of the Central Zone, Tigray, North Ethiopia, 2018: Unmatched Case-Control Study. In: Unmatched Case-Control Study Endocrinol Metab. 2018; 4(2):1-7. https://www.imedpub.com/endocrinol ogy-metabolism-open-access/

45. Alemayehu AM, Dagne H, Dagnew B. Knowledge and associated factors towards diabetes mellitus among adult non-diabetic community members of Gondar city, Ethiopia 2019. PLoS One. 2020;15(3):1-12. https://doi. org/10.1371/journal.pone.0230880.

46. Takele GM, Weharei MA, Kidanu HT, Gebrekidan KG, Gebregiorgis BG. Diabetes self-care practice and associated factors among type 2 diabetic patients in public hospitals of Tigray regional state, Ethiopia: a multicenter study. PLoS One. 2021;16(4):1-11. https://doi.org/10.1371/journal. pone. 0250462.

47. Bonger Z, Shiferaw S, Tariku EZ. Adherence to diabetic self-care practices and its associated factors among patients with type 2 diabetes in Addis Ababa Ethiopia. Patient Prefer Adherence. 2018;12:963-70. https://doi. org/10.2147/PPA.S156043.

\section{Publisher's Note}

Springer Nature remains neutral with regard to jurisdictional claims in published maps and institutional affiliations.

Ready to submit your research? Choose BMC and benefit from:

- fast, convenient online submission

- thorough peer review by experienced researchers in your field

- rapid publication on acceptance

- support for research data, including large and complex data types

- gold Open Access which fosters wider collaboration and increased citations

- maximum visibility for your research: over $100 \mathrm{M}$ website views per year

At BMC, research is always in progress.

Learn more biomedcentral.com/submissions 